\section{Case Reports in Neurology}

Case Rep Neurol 2020;12:402-409

DOI: $10.1159 / 000510632$

Published online: November 9, 2020

(c) 2020 The Author(s)

Published by S. Karger AG, Basel

www.karger.com/crn

This article is licensed under the Creative Commons Attribution-NonCommercial 4.0 International License (CC BY-NC) (http://www.karger.com/Services/OpenAccessLicense) Usage and distribution for commercial purposes requires written permission.

\title{
Central Nervous System Vasculitis as a Rare Presentation of Mycoplasma pneumoniae: A Case Report
}

\author{
Ashraf Omer Elamin Ahmed ${ }^{a} \quad$ Mona Mohammad Ibraheem Babikir ${ }^{a}$ \\ Amir Elssoni Mahjoup Khojali ${ }^{b}$ Suresh Nalaka Menik Arachchige ${ }^{a}$ \\ Abdirahman Mohamud Abdirahman ${ }^{b}$ Mouhand Faisal Hamad Mohamed ${ }^{a}$ \\ aDepartment of Medicine, Hamad Medical Corporation, Doha, Qatar; ${ }^{b}$ Department of \\ Diagnostic Radiology, Hamad Medical Corporation, Doha, Qatar
}

\section{Keywords}

Mycoplasma pneumoniae CNS vasculitis · Extrapulmonary manifestion · Mycoplasma pneumonia complications

\begin{abstract}
Mycobacteria pneumoniae (MP) commonly causes upper and lower respiratory tract infections. The clinical manifestation is classified as pulmonary and extrapulmonary. These manifestations vary according to the involved system. MP may affect one system or more at a time. Commonly prodromal respiratory symptoms precede systemic involvement. Central nervous system involvement in uncommon. This report is presenting a rare case of central nervous system vasculitis secondary to MP, highlighting the diagnosis and management with a succinct literature review.




\section{Case Reports in Neurology}

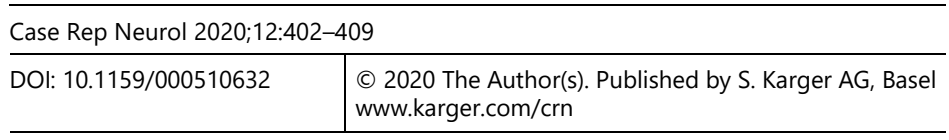

Ahmed et al.: Neurological Extrapulmonary Manifestation of Mycoplasma pneumoniae Infection

\section{Introduction}

Mycoplasma pneumoniae (M. pneumoniae, MP) is a bacterium that belongs to Mollicutes, which is a class of bacteria characterized by the absences of cell wall [1], necessitating particular groups of antibiotics [1]. It can cause upper or lower respiratory tract infections and is one of the most common causes of community-acquired pneumonia [2]. MP causes mild atypical pneumonia, usually called walking pneumonia [3]. In addition to affecting the respiratory tract, it can affect the cardiovascular, digestive, dermatological, neurological, and hematological systems, with central nervous system being the most common extrapulmonary system involved $[2,3]$. We here report an adult male who presented with a suspicion of meningoencephalitis with multiple neurological deficits and was eventually found to have MP. Additionally, we review the relevant literature to raise awareness about this entity.

\section{Case Presentation}

We report on a 28-year-old male patient with no past medical history. He was brought to the emergency department of Weill Cornell affiliated Hamad General Hospital with mild confusion. He complained of severe headache of 2 days duration associated with photophobia. He denied any neck stiffness, blurry vision, weakness, or numbness. His symptoms were preceded by a productive cough of yellow sputum associated with fever, chills, and chest discomfort for 1 week, no loss of consciousness or dizziness. A review of systems was unremarkable. He has a history of sick contact with patients having flu as he lives in a camp; he is not sexually active.

Examination revealed an average built man, conscious, oriented with short attention spans. He was looking sick with tachycardia (119 bpm) and tachypnea (28 breaths per minute) with shallow breathing maintaining Sp02 95\% on 5-L oxygen.

Additionally, he had a nasal voice tone. His throat was congested with non-exudative enlarged tonsils and no lymphadenopathy. Oral temperature was $40.6^{\circ} \mathrm{C}$, blood pressure $141 / 88$ $\mathrm{mm} \mathrm{Hg}$.

His pupils were isocoric and reactive with a normal funduscopic exam, but with horizontal nystagmus. The neurological exam was remarkable for lower motor neuron right facial palsy, absent gag reflex, and right hypoglossal nerve weakness. His power and sensations were intact. However, with generalized, exaggerated deep tendon reflexes, and up going plantar reflexes on the left side. There was no neck rigidity; Kernig's and Budinski's signs were negative. The chest examination was unremarkable. Other physical examinations were insignificant.

His laboratory investigations were remarkable for neutrophilic leukocytosis, elevated alanine aminotransferase (ALT) and aspartate aminotransferase (AST), and mild hyponatremia (Table 1).

Chest X-ray (CXR) showed increased broncho-vascular marking with no apparent infiltration. Plain computed tomography of the head was un-remarkable, CT pulmonary angiography to rule out pulmonary embolism was negative; however, a small area of consolidation was noted on the superior segment of the left lower lobe (Fig. 1). 


\section{Case Reports in Neurology}

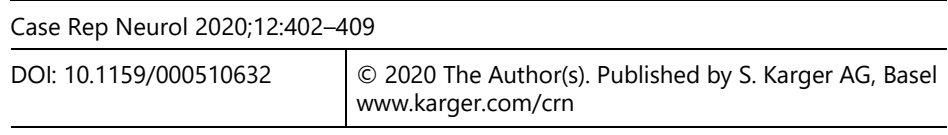

Ahmed et al.: Neurological Extrapulmonary Manifestation of Mycoplasma pneumoniae Infection

Given the history of fever and multiple neurological deficits, meningoencephalitis was suspected. Hence, a lumbar puncture was performed. The aspirated cerebrospinal fluid (CSF) looked clear; WBC $9(0-5)$ with lymphocyte $92 \%$, red blood cells 12, the protein and CSF glucose were normal at $0.34 \mathrm{~g} / \mathrm{L}(0.15-0.45 \mathrm{~g} / \mathrm{L})$ and $4.67 \mathrm{mmol} / \mathrm{L}$, respectively (Table 2). Gram stain and culture were negative. Viral PCR and initial tuberculosis workup, including AFB smear and the PCR were unrevealing. Since admission, the patient was started on empirical antibiotics, antiviral, and steroids, managed as a case of possible bacterial or viral meningitis.

MRI and MRA of the head were done and showed multiple acute-subacute lacunar infarctions and distal stenosis, suggesting a possible vasculitis (Fig. 2, 3). Hence, autoimmune workup was also sent and was also unrevealing (antinuclear antibodies, antinuclear cytoplasmic antibodies, complement levels).

While awaiting the workup, the result of oropharyngeal swab PCR revealed the presence of MP bacteria. After excluding other plausible etiologies for his presentation, considering that the neurological symptoms and signs followed the respiratory symptoms, MP with CNS vasculitis was deemed the most likely diagnosis. The patient continued Macrolide antibiotics and pulse steroids. His attention improved at discharge, and 1 month after discharge, he was free of any neurological deficits. Four months after discharge, he is followed up in our clinic and is doing fine.

\section{Discussion}

Neurological abnormalities have been reported to be associated with MP [3]. In reviewing the literature, we have found few reports describing the damage to different areas in the brain (striatum, pons, thalamus, basal ganglia, corpus callosum, and the brain stem) associated with MP infection. The clinical presentation differs according to the area affected; however, the most common presentation is confusion and decreased level of consciousness with or without prodromal upper respiratory tract (URT) symptoms [4-7]. The exact mechanism is not clear. However, certain hypotheses have been made based on the presentation of certain cases. For example, disseminated encephalomyelitis with CSF positive for MP PCR suggests the possibility of a direct bacterial damage to the brain parenchyma and meninges [7, 8]. Rhomboencephalitis and cerebellitis have been reported in MP infection and are speculated to be due to an immune-mediated phenomenon [9, 10]. Additionally, opsoclonus-myoclonus syndrome (OMS), a unique neurological manifestation was reported in infants and adults in association with MP and is proposed to be due to autoimmune response [11].

Our patient presented with febrile illness, pneumonia, depressed level of consciousness, and various cranial nerve deficits. Head imaging confirmed vasculitic changes. Moreover, the nasopharyngeal swab tested positive for MP; he had low platelets and mild transaminitis which are common during the course of MP infection [12-14]. All these features made MP the most likely diagnosis. One of the possible mechanisms of vasculitis in the setting of MP is vascular occlusion by the bacteria as previously reported [13, 14]. However, that could not be ascertained as we did not attempt to send the mycoplasma PCR from the CSF.

In addition to antibiotics, extra-pulmonic systemic involvement usually is treated with immunomodulators. This is driven by the autoimmune nature of such involvement. Moreover, 


\section{Case Reports in Neurology}

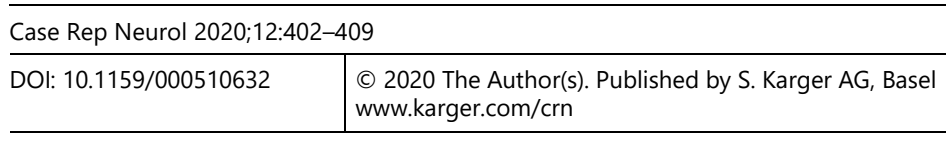

Ahmed et al.: Neurological Extrapulmonary Manifestation of Mycoplasma pneumoniae Infection

anticoagulants may alleviate signs due to vascular occlusion, yet it is still a controversial area $[3,14]$.

\section{Conclusion}

CNS vasculitis is an extrapulmonary manifestation of MP infection. Clinicians should be able to recognize this entity along with other extrapulmonary manifestations of MP. Antibiotics with immunomodulators may have a beneficial effect as autoimmunity plays an integral role in the pathogenesis.

\section{Acknowledgements}

Internal Medicine residency program for scientific support. article.

We thank the Qatar National Library for funding the open access publication fees of this

\section{Statement of Ethics}

The patient gave his written informed consent to publish his case (including publication of images).

\section{Conflict of Interest Statement}

All authors have no conflicts of interest to disclose.

\section{Funding Sources}

Qatar National Library.

\section{Author Contributions}

Ashraf O. E. Ahmed: First author, manuscript preparation, manuscript editing, literature search, manuscript review, and patient management. Mona Mohammad Ibraheem Babikir: manuscript writing, literature review, and manuscript review. Amir E. M. Khojali: Diagnostic images interpretation and reporting. Suresh Nalaka Menik Arachchige: manuscript writing. Abdirahman Mohamud Abdirahman: manuscript writing. Mouhand Faisal Hamad Mohamed: Supervisor, literature review, and manuscript review. 


\section{Case Reports in Neurology}

\section{References}

1 Waites KB, Talkington DF. Mycoplasma pneumoniae and its role as a human pathogen. Vol. 17, Clinical Microbiology Reviews. American Society for Microbiology (ASM); 2004. p. 697-728. https://doi.org/10.1128/CMR.17.4.697-728.2004.

2 Kashyap S, Sarkar M. Mycoplasma pneumonia: Clinical features and management. Vol. 27, Lung India. Wolters Kluwer - Medknow Publications; 2010. p. 75-85.

3 Narita M. Classification of extrapulmonary manifestations due to Mycoplasma pneumoniae infection on the basis of possible pathogenesis. Front Microbiol. 2016 Jan; 7:23.

4 Perez C, Montes M. Cutaneous leukocytoclastic vasculitis and encephalitis associated with Mycoplasma pneumoniae infection. Arch Intern Med. 2002 Feb;162(3):352-4.

5 Bae JW, Kim HJ, Chang GY, Kim EJ. Combined Striatum, Brain Stem, and Optic Nerve Involvement due to Mycoplasma pneumoniae in an Ambulatory Child. Case Rep Neurol. 2011 May;3(2):109-12.

6 Ashtekar CS, Jaspan T, Thomas D, Weston V, Gayatri NA, Whitehouse WP. Acute bilateral thalamic necrosis in a child with Mycoplasma pneumoniae. Dev Med Child Neurol. 2003 Sep;45(9):634-7.

7 Narita M. Mycoplasma pneumoniae as an Under-Recognized Agent of Vasculitic Disorders. Adv Etiol Pathog Pathol Vasc. 2011. https://doi.org/10.5772/22875.

8 Stamm B, Moschopulos M, Hungerbuehler H, Guarner J, Genrich GL, Zaki SR. Neuroinvasion by Mycoplasma pneumoniae in acute disseminated encephalomyelitis [Internet]. Emerg Infect Dis. 2008 Apr;14(4):641-3. [cited 2020 Apr 27] Available from: http://www.ncbi.nlm.nih.gov/pubmed/18394283

9 Christo PP, Silva JS, Werneck IV, Dias SL, Casa de Belo Horizonte S, Horizonte BM. Rhombencephalitis possibly caused by Mycoplasma pneumoniae [Internet]. Arq Neuropsiquiatr. 2010 Aug;68(4):656-8. [cited 2020 Apr 27]. Available from: http://www.scielo.br/pdf/anp/v68n4/v68n4a35.pdf

10 Mesraoua B, Abbas M, D' Souza A, Ruiz Miyares F, Hashem M, et al. Adult opsoclonus-myoclonus syndrome following Mycoplasma pneumoniae infection with dramatic response to plasmapheresis. Acta Neurol Belg 2011 Jun;111(2):136-8. Available from: https://www.ncbi.nlm.nih.gov/pubmed/21748933/

11 Huber BM, Strozzi S, Steinlin M, Aebi C, Fluri S. Mycoplasma pneumoniae associated opsoclonus-myoclonus syndrome in three cases. Eur J Pediatr. 2010 Apr;169(4):441-5.

12 Shin SR, Park SH, Kim JH, Ha JW, Kim YJ, Jung SW, et al. Clinical characteristics of patients with Mycoplasma pneumoniae-related acute hepatitis. Digestion. 2012;86(4):302-8.

13 Aviner S, Miskin H, London D, Horowitz S, Schlesinger M. Mycoplasma pneumonia infection: A possible trigger for immune thrombocytopenia. Indian J Hematol Blood Transfus. 2011 Mar;27(1):46-50.

14 Balaguer A, Boronat M, Carrascosa A. Successful treatment of pericarditis associated with Mycoplasma pneumoniae infection [Internet]. Pediatr Infect Dis J. 1990 Feb;9(2):141-3. [cited 2020 Jul 11] Available from: http://journals.lww.com/00006454-199002000-00016 


\section{Case Reports in Neurology}

Case Rep Neurol 2020;12:402-409

DOI: $10.1159 / 000510632$

(c)

(C) 2020 The Author(s). Published by S. Karger AG, Basel www.karger.com/crn

Ahmed et al.: Neurological Extrapulmonary Manifestation of Mycoplasma pneumoniae Infection

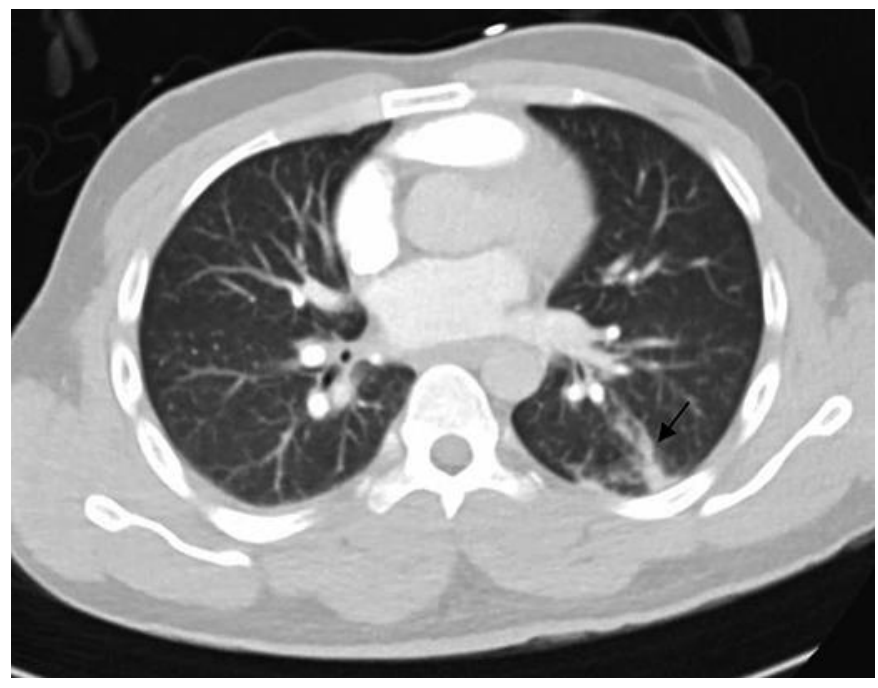

Fig. 1. Enhanced CT of the chest showing focal linear pulmonary opacity in the superior segment of the left lower lobe (arrow) resembling a small area of consolidation closely related to nearby subsegmental pulmonary vessels. 


\section{Case Reports in Neurology}

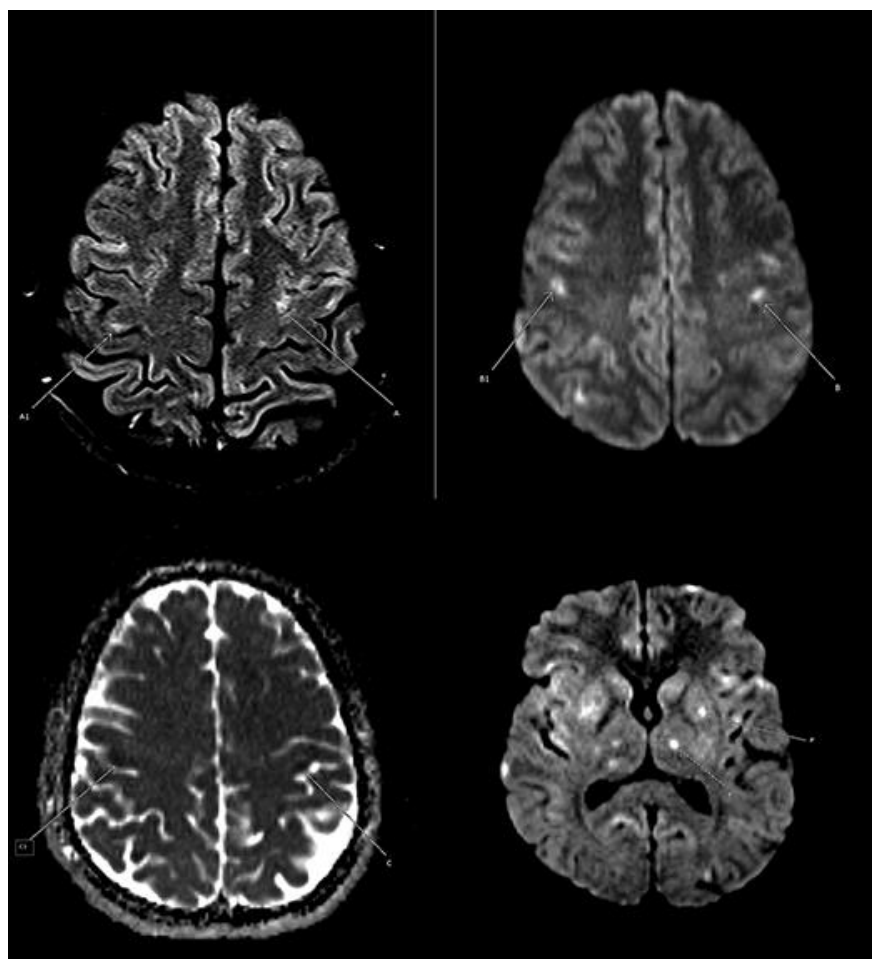

Fig. 2. MRI axial FLAIR, DWI and ADC images showing bilateral high cortical and subcortical foci of high signal in FLAIR ( $a$ and a1), high signal in DWI (b and b1) and low signal in ADC ( $c$ and c1), representing small acute infarcts. Tiny lacunar infarcts also noted in the left putamen (P) and left thalamus (T) (high signal foci in DWI, P and T in the last image). DWI, diffusion-weighted imaging; FLAIR, fluid-attenuated inversion recovery; ADC, apparent diffusion coefficient.
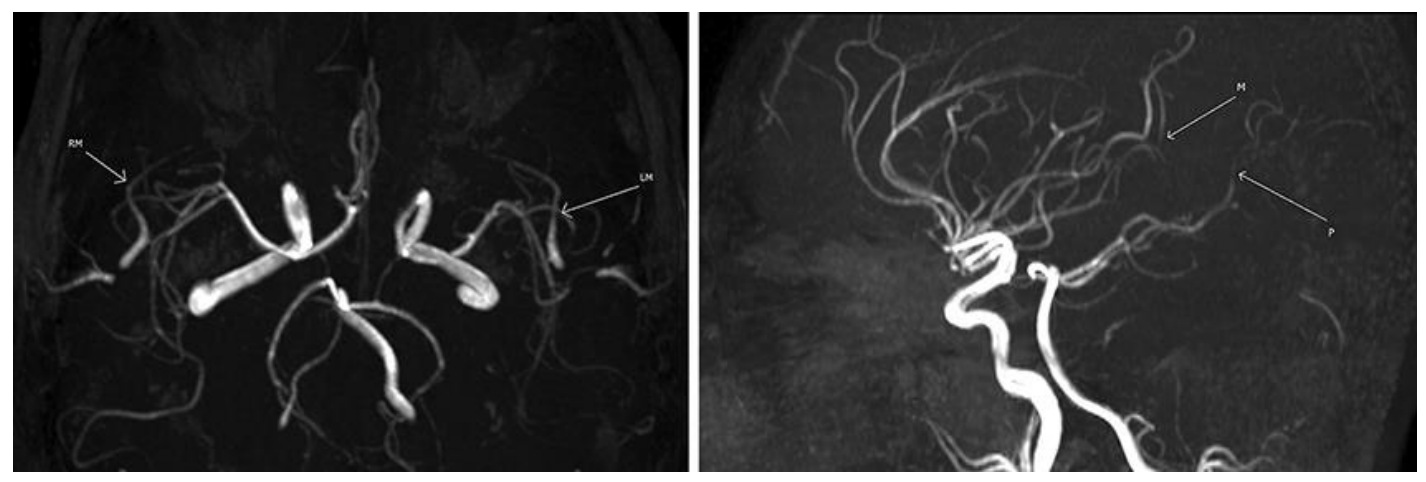

Fig. 3. MRA images showing some irregular caliber narrowing and beading of the mid and distal parts of the right and left MCA branches (RM, LM and M), as well as the mid and distal part of the right PCA (P). MRA, magnetic resonant arteriography, MCA, middle cerebral artery, PCA, posterior cerebral artery. 
Case Reports in

Neurology
Case Rep Neurol 2020;12:402-409

\begin{tabular}{l|l}
\hline DOI: $10.1159 / 000510632$ & (c) 2020 The Author(s). Published by S. Karger AG, Basel
\end{tabular} www.karger.com/crn

Ahmed et al.: Neurological Extrapulmonary Manifestation of Mycoplasma pneumoniae Infection

Table 1. Basic labs

\begin{tabular}{lcc}
\hline Variable & Value & Reference range \\
\hline WBC & $17.7 \times 10^{3} / \mu \mathrm{L}$ & $4-10 \times 10^{3} / \mu \mathrm{L}$ \\
$\mathrm{ANC}$ & $12.2 \times 10^{3} / \mu \mathrm{L}$ & $2-7 \times 10^{3} / \mu \mathrm{L}$ \\
$\mathrm{Hb}$ & $17 \mathrm{gm} / \mathrm{dL}$ & $13-17 \mathrm{gm} / \mathrm{dL}$ \\
Platelets & $139 \times 10^{3} / \mu \mathrm{L}$ & $150-400 \times 10^{3} / \mu \mathrm{L}$ \\
AST & $238 \mathrm{U} / \mathrm{L}$ & $0-40 \mathrm{U} / \mathrm{L}$ \\
ALT & $188 \mathrm{U} / \mathrm{L}$ & $0-41 \mathrm{U} / \mathrm{L}$ \\
Alk Phos & $50 \mathrm{U} / \mathrm{L}$ & $40-129 \mathrm{U} / \mathrm{L}$ \\
Direct bilirubin & $16 \mu \mathrm{mol} / \mathrm{L}$ & $0-3 \mu \mathrm{mol} / \mathrm{L}$ \\
Urea & $8.30 \mathrm{mmol} / \mathrm{L}$ & $2.76-8.07 \mathrm{mmol} / \mathrm{L}$ \\
Creatinine & $119 \mu \mathrm{mol} / \mathrm{L}$ & $62-106 \mu \mathrm{mol} / \mathrm{L}$ \\
Sodium & $132 \mathrm{mmol} / \mathrm{L}$ & $136-145 \mathrm{mmol} / \mathrm{L}$ \\
Potassium & $3.5 \mathrm{mmol} / \mathrm{L}$ & $3.5-5.1 \mathrm{mmol} / \mathrm{L}$ \\
\hline
\end{tabular}

Table 2. Cerebrospinal fluid laboratory

\begin{tabular}{lll}
\hline Variable & Value/result & Reference range \\
\hline Gross & Looks clear & - \\
WBC & $9 / \mu \mathrm{L}$ & $0-5 / \mu \mathrm{L}$ \\
RBC & $12 / \mu \mathrm{L}$ & $0-2 / \mu \mathrm{L}$ \\
Neutrophils & $2 \%$ & $0-6 \%$ \\
Lymphocytes & $92 \%$ & $40-80 \%$ \\
Monocytes CSF & $6 \%$ & $15-45 \%$ \\
Protein CSF & $0.34 \mathrm{gm} / \mathrm{L}$ & $0.15-0.45$ gm/L \\
Glucose CSF & $4.67 \mathrm{mmol} / \mathrm{L}$ & See serum glucose \\
\hline
\end{tabular}

